\title{
THE MECHANISM OF THE WENCKEBACH TYPE OF A-V BLOCK
}

\author{
BY \\ GEORGE M. DECHERD AND ARTHUR RUSKIN \\ From the Department of Medicine, University of Texas School of Medicine, and the Heart Station, John Sealy \\ Hospital, Galveston, Texas, U.S.A. \\ Received August 24, 1945
}

The Wenckebach type of auriculo-ventricular block is characterized by a progressive lengthening of the A-V conduction time, ending in a completely blocked auricular complexthe Wenckebach period. These periodically recurring dropped beats were first recognized clinically by Wenckebach in 1899 from a careful analysis of radial arteriograms; Engelmann (1896) had noted the same phenomenon in the frog's heart a few years earlier. Changing conduction times, due to varying degrees of recovery of the A-V junction, were postulated by them to account for the dropped beats. A typical feature of the progressive prolongation of the $\mathrm{P}-\mathrm{R}$ interval is that the most marked increase in the conduction time is seen in the second complex of the group. Later ones show only slightly greater prolongation. The shortest A-V conduction time is seen in the first complex after the dropped beat; i.e. following the longest pause or the longest $\mathrm{R}-\mathrm{P}$ interval.

Clinically, the Wenckebach type of A-V block is seen especially in digitalis poisoning, in infective myocarditis, due particularly to rheumatic fever and diphtheria, in myocardial fibrosis or infarction due to coronary artery disease, and occasionally in other lesions of the conduction system. It occurs at low auricular rates, most often under the influence of digitalis, or at the high auricular rates of paroxysmal tachycardia (Wenckebach and Winterberg, 1927; Decherd, et al., 1943). A-V block, often of the Wenckebach type, has been produced experimentally by increasing the auricular rate (von Kries, 1902; Erlanger, 1906; Lewis, White, and Meakins, 1913; Lewis and Master, 1925; Ashman, 1925), by vagus stimulation (Mines, 1914; Lewis, 1925; Rothberger, 1931), by cold (Ganter and Zahn, 1912), by pressure (Gaskell, 1882; Erlanger and Blackman, 1909), by ischæmia (Engelmann, 1896), by asphyxia (Lewis and Mathison, 1910; Lewis, White, and Meakins, 1913), by acidosis (Mines, 1913), by various glucosides (W. Straub, 1901; Alcock and Meyer, 1903), by vagominetic drugs (Starr, 1936; Decherd and Ruskin, 1943), by auricular ectopic beats (Erlanger, 1906; Rothberger 1931; Zeisler, 1931; Schellong, 1931) and by interpolated ventricular ectopic beats (de Boer, 1915; H. Straub, 1918).

The intimate cellular processes that underlie conduction of myocardial excitation are at present obscure; the same obscurity of the fundamental mechanisms involved applies to defective conduction or heart block. The simple physiological properties of excitability, conductivity, refractoriness, and the like are, however, susceptible to study, and it is in such terms that the problems associated with complete or incomplete conduction must be discussed.

Various explanations of Wenckebach periods, which Wenckebach (1899) hirnself compared to the Luciani periods of rhythmicity of the markedly depressed heart, have been proposed from time to time. W. Straub (1901) produced Wenckebach periods and $2: 1$ $\mathrm{A}-\mathrm{V}$ block in the isolated frog heart by means of antiarin, and likewise explained these phenomena in terms of decreased excitability or increased refractoriness of the ventricle to regular stimuli. Von Kries (1902) produced Wenckebach periods and 2:1 A-V block by warming the auricle and cooling the ventricle, and explained them in terms of the arrival of auricular stimuli earlier and earlier in ventricular diastole and the ventricular refractory 
period, thus interfering with ventricular recovery. Trendelenburg (1903) produced Wenckebach periods in ventricular muscle strips, presumably lacking specialized conduction fibres, by increasing the frequency of electrical stimulation, and felt that variable latency was responsible for the block, not diminished conductivity. Hering (1904) invoked the diastolic recovery of reactivity, or Reaktionsbereitschaft, of the ventricular muscle, linking in this term the myocardial properties of irritability, conductivity, and contractility. A rise in auricular rate, diminution of ventricular excitability, or a fall in stimulus strength could, in his opinion, delay the recovery of the ventricular muscle and increase its refractory phase to auricular stimuli, with the production of dropped beats.

The idea of ventricular latency elaborated by Erlanger $(1906,1912)$, had to be abandoned when Hering (1910) and later workers (Lewis, White, and Meakins, 1913; Lewis and Master, 1925) localized the delay in A-V conduction within the A-V node, probably at the junction of its auricular and ventricular components (Kung and Mobitz, 1930). Mobitz (1924) centered the latency, which he related to the refractory phase of electrical excitability, in the $\mathrm{A}-\mathrm{V}$ node. Variable A-V conductivity, in his opinion, resulted from variable A-V nodal latency, since he found the difference between maximum and minimum latency was greater than A-V conduction time, and felt, contrary to Lewis (1912), that all parts of the heart conducted at the same rate. He also based his conclusions upon a cryptic interpretation of two types of recovery curves. Gilson (1942) has lately proposed an "excitation time" theory of A-V delay to take the place of the latency theory.

Mobitz' more important contribution was the first recovery curve of conductivity, drawn from an electrocardiogram with a varying auricular rate, showing the reciprocal relation of $\mathbf{P}-\mathbf{R}$ to the preceding R-P intervals. From the logarithmic curve, which our curves closely resemble, he pointed out that recovery is fastest in the earliest portion of the relative refractory period, and slowest at the end.

Schellong (1924) published a series of experiments on normal and digitalized ventricular strips of the frog heart, which were partially divided or pressed into a bridge simulating the A-V junction. He drew recovery curves of excitability, which closely resembled those of stimulus propagation (Erregungsfortpflanzung), thus linking the properties of conductivity and excitability. Whereas rhythmical stimulation of normal muscle strips caused no decrease in excitability, so that all stimuli were conducted, similar stimulation of digitalized strips resulted in partial block with Wenckebach periods. He concluded that digitalis delayed the recovery of excitability, so that successive stimuli fell earlier and earlier in the relative refractory period, resulting finally in a dropped beat. He postulated, therefore, that frequency of stimulation and the presence of a relative refractory period were the two factors underlying the Wenckebach type of block. He also pointed out that the period of electrical latency was less than 0.002-0.004 sec.; furthermore, that the latency between the auricle and the A-V node was measurable only when the stimulus was minimal, whereas the physiological stimuli were actually four to five times the threshold strength.

Samoiloff (1929) has attempted to explain the production of the Wenckebach type of block in ventricular bridges in terms of gradual prolongation of the absolute and relative refractory periods. Lewis and Master (1925) have demonstrated the lengthening of the refractory periods of the A-V tissues with slower auricular rates, and on this basis, and the shorter preceding recovery period, explained the maximum prolongation of the $\mathrm{P}-\mathrm{R}$ interval in the second conducted beat of the Wenckebach period. Ashman (1925) plotted curves of recovery of conductivity in turtle heart muscle compressed at the A-V junction. The longer the interval between break shocks to the auricle, the shorter was the A-V interval. The latter increased as the rest period between stimuli became shorter than that permitting complete recovery, and finally $2: 1 \mathrm{~A}-\mathrm{V}$ block resulted. Whether this point was the absolute refractory period of conductivity or represented a certain inimical concentration of hydrogen ions, as Mines (1913) supposed, was left an open question by Ashman, and still remains so.

Mobitz $(1924,1928)$ defined the Wenckebach type of A-V block as Type I, usually functional in pathogenesis, and adduced evidence to show that Type II, known now as the Mobitz type, in which dropped beats occur without previous prolongation of the $P-R$ interval, is usually due to organic interruption of the A-V junction. However, he admitted the not infrequent association of the two types in the same record. Experimentally it has also been 
pointed out that transitions from Type I to II may be obtained by increasing the rate of stimulation in digitalized ventricular strips (Schellong, 1924) and likewise in the A-V node and bundle (Scherf and Shookhoff, 1925). Even Wenckebach (1903, 1906), however, leaned toward a different explanation for Type II block, viz., diminished excitability. This explanation has been championed by Hay (1906) for both types of A-V block, and recently accepted as one factor by Campbell (1943).

Heim (1936) published recovery curves based upon Shellong's work (1924) with digitalized frog ventricle muscle strips, and compared them with curves, drawn separately for each Wenckebach period, from patients with Wenckeback type of A-V block due to digitalis administration. In both he frequently found a relatively vertical part of the recovery curve in the middle of the Wenckebach period, in which the P-R interval was prolonged without any marked shortening of the R-P interval. He interpreted this to mean sudden prolongation of the absolute and relative refractory periods from beat to beat. Blumberger (1937) has also drawn similar recovery curves of conductivity in two cases of Wenckebach block, which purported to show some changes in refractoriness from beat to beat.

We have published (1943) recovery curves in a case of reciprocal rhythm, showing the effects of various chemical and nervous influences on the A-V node. In general they resembled the recovery curves of Mobitz (1924), Lewis and Master (1925), Ashman (1925), and Schellong $(1924,1931)$ in their logarithmic form and absence of momentary variations of any great degree. We have seen such momentary variations in refractoriness in one case (1944), but do not believe that they are the basic mechanism that leads to Wenckebach periods.

\section{Results. (A) Recovery Curves from Clinical Cases}

Diagrams that represent recovery of A-V conductivity may readily be constructed by plotting the $P-R$ interval against the preceding $R-P$ interval. These values are obviously not exact measurements of either the conduction time through the A-V node, or the recovery time of these tissues, since they include the time intervals required for the passage of each impulse from the S-A node to the A-V node, and also that required for transmission from the A-V node to the ventricular muscle. Hence the curves obtained are at best approximations, but since the errors involved are probably reasonably constant, the approximations may be regarded as satisfactory and usable.

In general, recovery curves obtained in this fashion are logarithmic in contour. There are many factors that vary from case to case. Our files contain about 50 cases showing partial heart block of the Wenckebach type. In most instances, the patients had had rheumatic or arteriosclerotic heart disease, occasionally with recent myocardial infarction, or had been given digitalis, often in excessive amounts. Digitalis over-dosage was also a factor in the precipitation of paroxysmal auricular tachycardia in a large series of cases previously reported (1943), many of whom showed the Wenckebach type of block, a fact that suggested to us the importance of the auricular rate in the pathogenesis of heart block. In 30 cases, and often in multiple curves, the $\mathbf{P}$ waves were sufficiently clear-cut to allow the measurements necessary for the construction of recovery curves. In Fig. 1 we have assembled several of these curves for the purpose of illustrating two points: (1) the individual curves are smooth, without the humps described by Heim (1936) and Blumberger (1937); and (2) the curves show, as a group, tremendous variation in contour and position in the co-ordinate system. Fig. 2 shows curves drawn for consecutive Wenckebach periods in three patients. They illustrate further our failure to observe the type of curve shown by Blumberger and Heim. They also serve to show that whereas the general type of the curve is smooth and constant from moment to moment, the individual points show sufficient variation to indicate that minor influences may affect the exact extent of recovery during each cardiac cycle. These play roles difficult to evaluate, but we consider them in general unimportant in comparison with the physiological attributes of the conduction tissue that are expressed by the recovery curve.

Ventricular premature beats, as is well known, may affect subsequent A-V conduction. Thus in the middle curve of Fig. 2, a point obtained from a cycle following a ventricular premature beat shows much delayed conduction. Conversely, improved conductivity is seen in the location of points above and to the left of the curve when Wenckebach block 


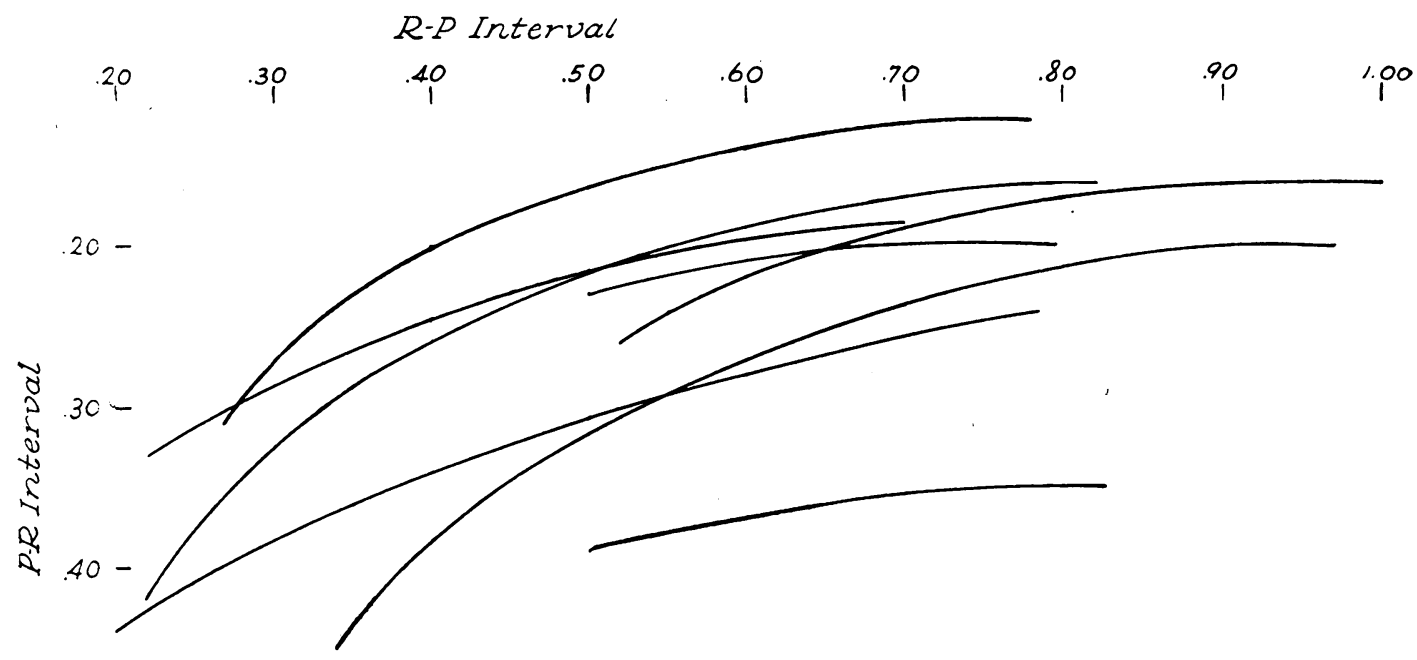

FIG. 1.- Recovery curves of A-V conduction, drawn from electrocardiograms showing the Wenckebach type of block, by relating the $\mathbf{P}-\mathbf{R}$ intervals to the preceding $.50-\quad$ R-P interval.

\section{$R D$ Interval}

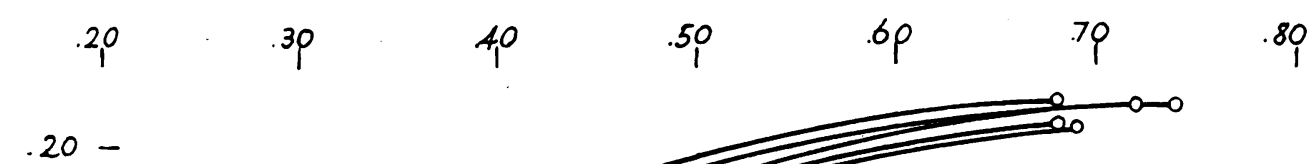

30

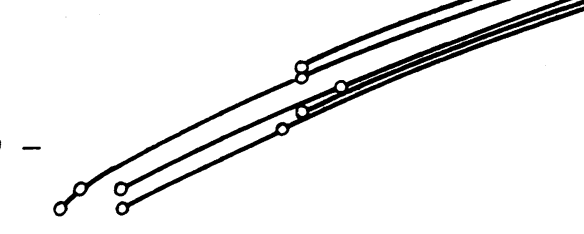

$.20-$

$30-$

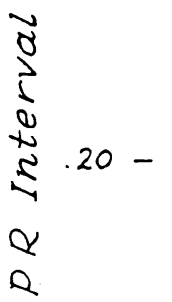

$30-$

FIG. 2.-Curves drawn for consecutive Wenckebachs periods showing the extent of variability of the individual points, and the general stability of the conformation of the curves from moment to moment. The isolated point followed a ventricular premature beat. 
suddenly changes to $1: 1$ conduction, possibly through reflex diminution in vagal tone. It seems probable that the exact location of each point may be slightly affected by reflex vagal and sympathetic influences, the respiratory cycle, the carotid sinus reflex, and cyclic local metabolic changes. Although these and similar factors may-and undoubtedly do-produce minor changes in refractoriness, recovery, and conductivity, we do not believe that they are fundamental to the mechanism that leads to the Wenckebach type of block.

\section{(B) THeORetical Recovery CuRves}

Inspection of recovery curves derived from clinical cases exhibiting the Wenckebach phenomenon reveals a wide variation in several particulars: the absolute refractory period, the contour of the curve during recovery, the time required for complete recovery, and the conduction time after complete recovery. It is obvious that an additional variable factor, i.e. the auricular rate, must also govern the time available for recovery of the conducting tissues, and hence affect the degree of A-V block. These considerations have led us to select four arbitrarily drawn recovery curves, all with the same absolute refractory period of $0.20 \mathrm{sec}$., and the same conduction time of $0.20 \mathrm{sec}$. after complete recovery, but with slopes varying from rapid to slow recovery. Using each curve, the effect of varying auricular rate upon the $\mathbf{P}-\mathbf{R}$ interval has been studied.

As a starting point for each set of calculations, the assumption has been made that a blocked impulse has fallen just within the absolute refractory period, 0.19 sec. after the preceding $R$ wave. This allows the further assumption of a maximal rest period before the set of complexes with which calculations are begun. In other words, an initial R-P interval is assumed of $0.19 \mathrm{sec}$. plus the P-P interval being studied. With these premises, the theoretical recovery curves in Fig. 3 have been used to calculate the A-V conduction times for many different auricular rates by reading from the curve the $P-R$ interval that corresponds to each R-P interval. Several examples will make this procedure clear.

1. Curve A; auricular rate 80 a minute ( $P-P$ interval $0.75 \mathrm{sec}$.); maximal possible recovery time $0.75+0.19$, or $0.94 \mathrm{sec}$.

\begin{tabular}{|c|c|c|}
\hline $\begin{array}{c}\text { R-P interval } \\
0.94 \\
0.55 \\
0.55\end{array}$ & $\begin{array}{c}\text { P-R interval } \\
0 \cdot 20 \\
0 \cdot 20 \\
0 \cdot 20\end{array}$ & $\begin{array}{l}\text { Next R-P interval } \\
0.75-0.20=0.55 \\
\text { etc., } \ldots .0 .55\end{array}$ \\
\hline
\end{tabular}

Hence, at this auricular rate, the $\mathrm{P}-\mathrm{R}$ interval will always be 0.20 sec.

2. Curve A; auricular rate 109 a minute (P-P interval $0.55 \mathrm{sec}$ ); maximal possible recovery time $0.55+0.19$, or $0.74 \mathrm{sec}$.

$\begin{array}{ccc}\text { R-P interval } & \text { P-R interval } & \text { Next R-P interval } \\ 0.74 & 0 \cdot 20 & 0.55-0 \cdot 20=0.35 \\ 0.35 & 0 \cdot 217 & 0.55-0 \cdot 217=0.333 \\ 0.333 & 0 \cdot 224 & 0.55-0.224=0.326 \\ 0.326 & 0 \cdot 227 & 0.55-0 \cdot 227=0.323 \\ 0.323 & 0.228 & 0.55-0.228=0.322 \\ 0.322 & 0.228 & 0.55-0.228=0.322 \\ 0.322 & 0.228 & \text { etc. } \ldots\end{array}$

Hence, at this auricular rate, the $P-R$ interval will become stabilized at $0.228 \mathrm{sec}$.

3. Curve $\mathrm{A}$; auricular rate 120 a minute (P-P interval $0.50 \mathrm{sec}$.); maximal possible recovery time $0.50+0.19$, or $0.69 \mathrm{sec}$.

$\begin{array}{cc}\text { R-P interval } & \text { P-R interval } \\ 0.69 & 0.20 \\ 0.30 & 0.24 \\ 0.26 & 0.267 \\ 0.233 & 0.295 \\ 0.205 & 0.36 \\ 0.14 & \text { blocked } \\ 0.64 & 0.20 \\ 0.30 & 0.24\end{array}$

Next R-P interval
$0.50-0.20=0.30$
$0.50-0.24=0.26$
$0.50-0.267=0.233$
$0.50-0.295=0.205$
$0.50-0.36=0.14$
$0.50+0.14=0.64$
$0.50-0.20=0.30$
etc...

Hence, at this auricular rate, there is a $6: 5 \mathrm{~A}-\mathrm{V}$ block of the Wenckebach type. 
4. Curve $D$; auricular rate 102 a minute (P-P interval 0.59 sec.); maximal possible recovery time $0.59+0.19$, or $0.78 \mathrm{sec}$.).

R-P interval
$0 \cdot 78$
$0 \cdot 39$
$0 \cdot 278$
$0 \cdot 228$
$0 \cdot 205$
$0 \cdot 193$
$0 \cdot 783$

P-R interval
0.20
0.312
0.362
0.385
0.397
blocked
0.20.

Next R-P interval
$0.59-0 \cdot 20=0.39$
$0.59-0.312=0 \cdot 278$
$0.59-0.362=0.228$
$0.59-0.385=0 \cdot 205$
$0.59-0.397=0.193$
$0.59+0 \cdot 193=0.783$
etc...

Using curve $D, 6: 5$ block occurs at a slower auricular rate than for Curve A.

5. Curve $\mathrm{D}$, auricular rate 120 a minute (P-P interval $0.50 \mathrm{sec}$.); maximal possible recovery time $0 \cdot 50+0 \cdot 19$, or $0.69 \mathrm{sec}$.

R-P interval
0.69
0.30
0.148
0.648
0.283
0.14
0.64

P-R interval
$0 \cdot 20$
0.352
blocked
0.217
0.36
blocked
0.219

Using Curve D, this auricular rate results in a $3: 2$ Wenckebach block.

$$
\begin{aligned}
& \text { Next R-P interval } \\
& 0 \cdot 50-0 \cdot 20=0 \cdot 30 \\
& 0 \cdot 50-0 \cdot 352=0 \cdot 148 \\
& 0 \cdot 50+0 \cdot 148=0 \cdot 648 \\
& 0 \cdot 50-0 \cdot 217=0 \cdot 283 \\
& 0 \cdot 50-0 \cdot 36=0 \cdot 14 \\
& 0 \cdot 50+0 \cdot 14=0.64 \\
& \text { etc. } . .
\end{aligned}
$$

Table I summarizes the data obtained in this fashion for each curve, and over a wide range of auricular rates.

Comparison of the theoretical curves in Fig. 3 with the curves from clinical sources in Fig. 1, indicates that much longer refractory periods and less complete recovery than has been assumed in constructing Fig. 3 are commonly encountered clinically. For example, if we assume, as seems well justified by Fig. 1, an absolute refractory period of $0.40 \mathrm{sec}$, and a P-R interval of $0.30 \mathrm{sec}$. at complete recovery, and employ a curve of the contour of curve $D$, we find that similar grades of block are obtained with much lower auricular rates.

6. Curve $\mathrm{D}$, auricular rate 67.5 a minute (P-P interval 0.89 sec.) ; maximal possible recovery time $0.89+0.39$, or $1.28 \mathrm{sec}$.

R-P interval
1.28
0.59
0.478
0.428
0.405
0.393
1.283

P-R interval
$0 \cdot 30$
0.412
$0 \cdot 462$
$0 \cdot 485$
$0 \cdot 497$
blocked
0.30

Next R-P interval
$0.89-0.30=0.59$
$0.89-0.412=0.478$
$0.89-0.462=0.428$
$0.89-0.485=0.405$
$0.89-0.497=0.393$
$0.89+0.393=1.283$
etc.

These physiological constants produce a $6: 5$ block at a slower auricular rate than in example 4 .

7. Curve $\mathrm{D}$, auricular rate 75 a minute (P-P interval $0.80 \mathrm{sec}$ ) ; maximal possible recovery time $0.80+0.39$, or $1 \cdot 19 \mathrm{sec}$.

R-P interval
1.19
0.50
0.348
1.148

P-R interval
$0 \cdot 30$
$0 \cdot 452$
blocked
$0 \cdot 30$
Next R-P interval
$0 \cdot 80-0 \cdot 30=0.50$
$0 \cdot 80-0 \cdot 452=0 \cdot 348$
$0 \cdot 80+0 \cdot 348=1 \cdot 148$

Hence, we derive a $3: 2$ block at this auricular rate, which is much slower than in example 5 .

These examples suffice to show that the grades of block listed in Table I may readily be anticipated at auricular rates well within the range of those observed clinically.

Similar depression of the conducting tissues with prolonged refractoriness and delayed recovery will account for the presence of the higher grades of $\mathrm{A}-\mathrm{V}$ block at auricular rates much lower than those required in Table $I$. An absolute refractory period of $0.60 \mathrm{sec}$., and a P-R interval at complete recovery of $0.40 \mathrm{sec}$., permits the calculation of a block as high as $6: 1$. We have encountered (1943) one example of $6: 1$ block in a patient with paroxysmal tachycardia whose conducting tissues were reflexly depressed by carotid sinus pressure.

To return to Table I, certain general observations should be made. 
TABLE I

Calculated Degree of A-V Block for Varying Auricular Rates

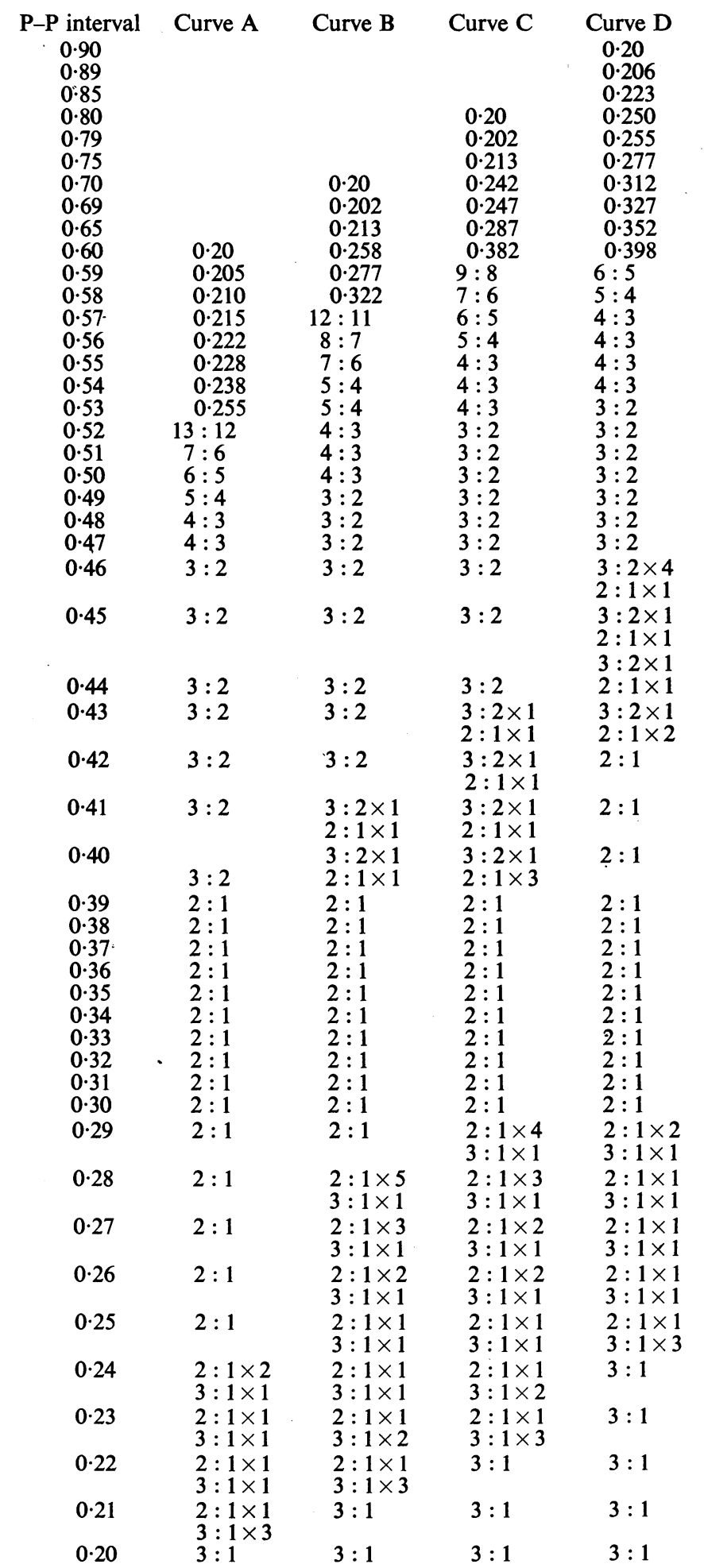

TABLe I.-Calculated P-R intervals and grades of A-V block, obtained at the auricular rates indicated, calculated from the curves of Fig. 3 in the manner described in the text. Admixtures of block are indicated; for example, $3: 2$ alternating with $2: 1$ block is listed as $3: 2 \times 1 / 2: 1 \times 1$. 


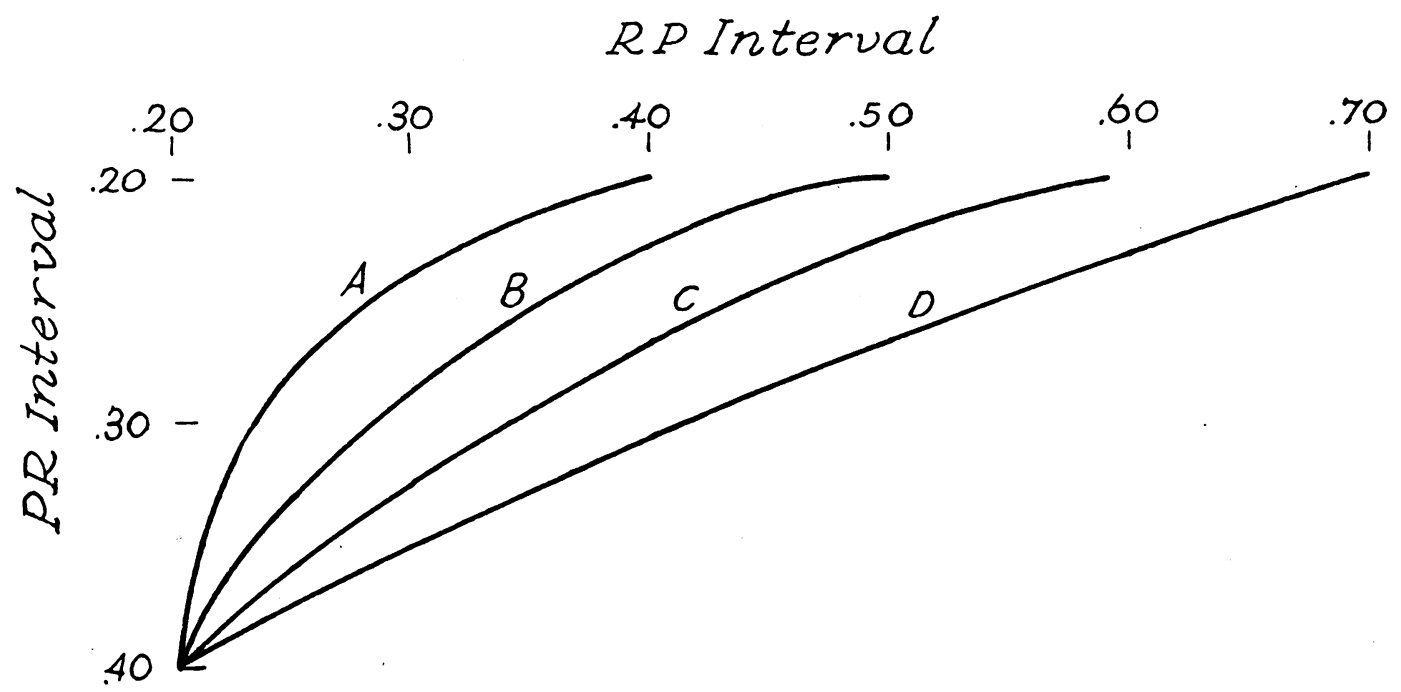

Fig. 3.-Idealized curves, used for the calculations described in the text.

1. Variations in the auricular rate, for each of the recovery curves studied, lead to a wide variety of conduction disturbances. With increasing auricular rates, A-V conduction is progressively impaired.

2. At slow rates, whenever the $\mathbf{P}-\mathbf{P}$ interval is such that the resulting $\mathbf{R}-\mathbf{P}$ interval falls in the range of complete recovery, the $P-R$ interval is normal.

3. At slightly faster rates, whenever the resultant $\mathbf{R}-\mathbf{P}$ interval falls in the range of partial refractoriness, or incomplete recovery, there is partial heart block with prolongation of the P-R interval. This is longer with the curves of less rapid recovery, i.e. longest with curve $D$. The limiting factor is the P-R interval at R-P intervals just exceeding the refractory period, and with our curves could not exceed $0.40 \mathrm{sec}$. Under other conditions, the longest $\mathrm{P}-\mathrm{R}$ interval without dropped beats could be longer than $0.40 \mathrm{sec}$, and, of course, not infrequently is much greater. As the curves show progressively slower recovery, prolongation of the P-R interval without dropped beats is possible only at slower and slower rates, since dropped beats occur more readily.

4. Further shortening of the P-P interval leads to low grade A-V block, with dropped beats of the Wenckebach type. At any given auricular rate in this range, the degree of block is higher as we pass from curve $A$ to curve $D$.

5. As the P-P interval is further shortened, $2: 1$ block is found, first mixed in varying proportions with $3: 2$ block, and then for a wide span of auricular rates as simple $2: 1$ block. At still higher auricular rates $3: 1$ block appears, first in admixture with $2: 1$ block, and finally, alone.

6. At any auricular rate, the grade of block is highest with curve $\mathrm{D}$, which shows slowest recovery. Even higher grades of block, at the same auricular rate, may be found if the curve $\mathrm{D}$ is shifted down and to the right in the direction of further depression of conductivity and recovery. This is shown in examples 6 and 7, above.

7. In general, the flatter the contour of the recovery curve, as in curves $C$ and $D$, the more typical of the classical Wenckebach period are the consecutive $P-R$ intervals. This is illustrated in example 4 above, derived from curve $D$, which is to be contrasted with example 3 , derived from curve $A$. In the latter, the greatest prolongation of the $\mathbf{P}-\mathbf{R}$ interval is seen at the end of the Wenckebach cycle, just before the dropped beat; in the former, the P-R intervals show typically the greatest increase in the second complex of the group. This is consistently borne out in all of the calculations upon which Table $I$ is based. This is due to the fact that near the absolute refractory period, curve $A$ has a more vertical slope than curve $D$. 


\section{COMMENT}

Cardiac physiologists have variously attempted to explain the Wenckebach type of partial heart block on the basis of changing properties of the conducting tissues. They have postulated momentary changes in excitability, latency, the absolute or relative refractory periods, recovery of excitability or of conductivity, and increasing rate of stimulation, produced by experimental factors, drugs, or myocardial disease. The latency theory is no longer considered tenable; possible changes in excitability are not accessible to clinical study; nor do we believe that momentary changes in refractoriness or conductivity need be invoked to explain the mechanism of Wenckebach block. The role of certain of the physiological properties of the heart muscle has been appreciated, but a unified concept has hitherto been lacking. Schellong was clearly aware of the importance of the relative refractory period as reflected in the recovery curve of excitability, and of the frequency of stimulation. Mobitz and Ashman demonstrated the effect upon the $P-R$ interval of the preceding recovery time. Numerous authors have emphasized the importance of increasing auricular rates.

Studies of clinical material permit the evaluation of the following factors that determine the sequence of A-V conduction in the Wenckebach type of block:

1. Duration of complete ref ractoriness.

2. Duration of partial refractoriness:

3. Contour of the recovery curve.

4. Conduction time after complete recovery.

5. Auricular rate (P-P interval).

It should be emphasized that the first four factors listed actually are encompassed by the curves of recovery of A-V conductivity. For this reason we consider these curves fundamental to any attempt at explanation of Wenckebach block. We have demonstrated above that all varieties of Wenckebach block may be deduced by varying these five factors, i.e. the recovery curve and the auricular rate. In fact, other varieties of partial A-V block seem to be susceptible to explanation on the same basis (Table I).

The curves of Fig. 3 are not purely artificial; they are idealizations of the several varieties of curves that were drawn from clinical cases, and represent some of the possible fluctuations in speed and completeness of recovery. Their contour and co-ordinate values are typical of many of the recovery curves published previously, both by ourselves and other authors. By assuming certain auricular rates, curves may be drawn from Campbell's formula (1943) for the length of consecutive P-R intervals; these resemble our curve $C$ or, to a lesser extent, curve $B$. The admixture in all proportions of closely adjoining grades of block, such as $3: 2$ with $2: 1$, or $2: 1$ with $3: 1$, seen in Table $I$, is also encountered clinically. The frequency with which the various grades of block are found in Table I, as well as their stability over a wide range of auricular rates, agree well with clinical experience.

Cases are encountered clinically that show marked transitions in the grade of block, sometimes cyclic in character, e.g. from $4: 3$ to $2: 1$, or from $3: 2$ to $1: 1$, and back again. These shifts cannot be deduced from a single recovery curve, and require the assumption of transient change in those myocardial properties that fix the recovery curve. These changes in refractoriness and recovery and, equally important, in the auricular rate-may be due to a wide variety of chemical or reflex nervous factors. Similar factors, as we have pointed out above, may well be responsible for the minor deviations of individual points from the smooth recovery curves of clinical cases. The point at which these otherwise minor deviations are most conspicuous is at the absolute refractory period, where there may be some overlapping of the R-P intervals of conducted and dropped beats.

The five factors that we have listed above, which determine the character of the Wenckebach periods, are mutually interdependent and may change simultaneously in the same or opposite directions. Thus, acceleration of the auricular rate, which would tend to increase A-V block, in itself shortens refractoriness and recovery (Lewis and Master, 1925), in effect shifting the recovery curve upwards and to the left. Increased vagal tone shifts the recovery curve in the direction of less rapid recovery and greater block, but may be associated with a slower auricular rate, which would allow more complete recovery. These momentary shifts in refractoriness from beat to beat, correlated with changing recovery times, have 
served Lewis and Master, and Rothberger as the entire basis for their explanations of Wenckebach block. Our data show it is unnecessary to invoke such shifts to explain the Wenckebach phenomenon.

Aside from these minor variations, the recovery curve of the typical case of Wenckebach block is smooth in contour, and shows remarkable stability in the absolute and relative refractory periods, and in the A-V conduction time after complete recovery. Under these circumstances, variations in the auricular rate assume paramount importance in determining the grade of block in the Wenckebach periods at any time. Contrary to the reports of Heim and Blumberger, in our experience neither the contour of the recovery curves, nor their place in the co-ordinate system, change significantly from cycle to cycle in the typical case.

On the other hand, the diverse recovery curves of different patients, or of the same patients under different circumstances, account for the varying degrees of block that may occur at the same auricular rate. Thus, with one recovery curve, the $P-R$ interval may reach a maximum of $0.30 \mathrm{sec}$. before a dropped beat, while with another curve, there may be $1: 1 \mathrm{con}$ duction with a constant $\mathrm{P}-\mathrm{R}$ interval of $0.45 \mathrm{sec}$, , or higher. This same type of phenomenon may occur, with a constant recovery curve, as a result of variation in the auricular rate.

It has been noted by other observers, both clinically and experimentally, that the Type II block of Mobitz is occasionally seen in association with the Wenckebach Type I block. Since all varieties of partial A-V block, with the exception of Type II, are seen in Table I to have the same fundamental explanation in terms of the auricular rate and the recovery curve of A-V conduction, it seems probable that Type II would have the same physiological basis. We have had no instance available for study, but we suggest the possibility that this type of block occurs when the recovery curve is an almost horizontal straight line, from the absolute refractory period to the end of recovery. We would predict, if this assumption were true, that minute increments of the P-R interval precede the sudden dropped beat. If this is not true, the explanation must depend on sudden changes in refractoriness of the severely damaged conducting tissues. Sudden changes in excitability seem to us to have no clinical or experimental support or parallel.

The empirical formula developed for Campbell by Professor Rushton for the prediction of consecutive $\mathrm{P}-\mathrm{R}$ intervals in the average Wenckebach period, serves to emphasize that the block progresses according to a simple logarithmic law. As mentioned previously, logarithmic recovery curves may be drawn from this formula by assuming an auricular rate. This formula fixes the P-R interval at complete recovery, the longest $\mathrm{P}-\mathrm{R}$ interval before dropped beats occur, and the duration of recovery. For each grade of block, the conformation of the recovery curve is likewise fixed, and as the grade of block decreases, with more rapid ventricular rates, the curves show a shift to the left. However, the formula does not fix the position of the curves in the co-ordinate system, and with this the absolute and relative refractory periods. These vary with the auricular rate assumed. We have been impressed with the wide diversity of the form and position of our clinical recovery curves, as well as the crucial significance of variations in the auricular rate. In the face of so many variables, we have not attempted to formulate a comprehensive mathematical expression for them all.

\section{SUMMARY}

The Wenckebach type of partial A-V block is explained on the basis of varying auricular rates and varying curves of recovery of $A-V$ conductivity. Other varieties of partial A-V block seem to be explicable in the same fashion.

We wish to thank Dr. L. N. Katz, Michael Reese Hospital, Chicago, for his interest and his valuable suggestions in the preparation of this paper.

\section{REFERENCES}

Alcock, N. H., and Meyer, H. (1903). Arch. Anat. Physiol., Physiol. Abt., p. 225.

Ashman, R. (1925). Amer. J. Physiol., 74, 121.

(1930). Amer. Heart J., 5, 581.

Blumberger, K. (1937). Z. klin. Med., 131, 500.

Campbell, M. (1943). Brit. Heart J., 5, 55.

de Boer, S. (1915). J. Physiol., 49, 310. 
Decherd, G. M., Herrmann, G. R., and Schwab, E. H. (1943). Amer. Heart J., 26, 446. and Ruskin, A. (1943). Tex. Reports Biol. and Med., 1, 319.

Engelmann, T. W. (1896). Arch. ges. Physiol., 56, 149.

Erlanger, J. (1906). J. exp. Med., 8, 8. (1912). Amer. J. Physiol., 30, 419. and Blackman, J. R. (1909). Heart, 1, 177.

Ganter, G., and Zahn, A. (1912). Arch. ges. Physiol., 145, 337. (1913). Ibid., 154, 492.

Gaskell, W. H. (1882). Phil. Trans., London, 3, 993. (1887). Ibid., 8, 404.

Gilson, A. S. (1942). Amer. J. Physiol., 138, 113.

Hay, J. (1906). Lancet, 1, 139.

Heim, F. (1936). Z. ges. exp. Med., 98, 551.

Hering, H. E. (1904). Prag. Med. Wschr., 29, 117; quoted by Mobitz. (1910). Arch. ges. Physiol., 131, 572.

von Kries, J. (1902). Arch. Anat. Physiol., Physiol. Abt., p. 477.

Kung, S. K., and Mobitz, W. (1930). Arch. exp. Path. Pharm., 155, 295.

Lewis, T. (1925). The Mechanism and Graphic Registration of the Heart Beat, Shaw and Sons, London.

- and Master, A. M. (1925). Heart, 12, 209.

and Mathison, G. C. (1910). Ibid., 2, 47.

, White, P. D., and Meakins, J. (1913). Ibid., 5, 289.

Mines, G. R. (1913). J. Physiol., 46, 188. (1914). Ibid., 47, 419.

Mobitz, W. (1924). Z. ges. exp. Med., 41, 180. (1928). Z. klin. Med., 107, 456.

Rothberger, C. J. (1931). Ergebn. der Physiol., 32, 472.

Ruskin, A., and Decherd, G. (1944). Tex. Reports on Biol. and Med., 2, 153.

Samoiloff, A. (1929). Arch. ges. Physiol., 222, 516.

Schellong, F. (1924). Z. Biol., 82, 27, 174, 435.

(1931). Z. ges. exp. Med., 782.

Scherf, D. and Shookhoff, C. (1925). Wien. Arch. inn. Med., 11, 425.

Starr, I. (1936). J. Pharm. Exp. Ther., 56, 77.

Straub, H. (1918). Münch. med. Wschr., 65, 643.

Straub, W. (1901). Arch. exp. Path. Pharm., 45, 346.

Trendelenburg, W. (1903). Arch. Anat. Physiol., Physiol. Abt., p. 271.

Wenckebach, K. F. (1899). Z. klin. Med., 37, 475.

- (1903). Die Arhythmie als Ausdruck bestimmter Funktionsstörugen des Herzens, W. Englemann, Leipzig; quoted by Mobitz.

- (1906). Arch. Anat. Physiol., Physiol. Abt., p. 297.

and Winterberg, H. (1927). Die unregelmässige Herztätigkeit, W. Engelmann, Leipzig.

Zeisler, E. B. (1931). Amer. Heart J., 6, 416. 